\title{
OTROS MODOS DE SER/AMAR: ROSARIO CASTELlaNOS
}

\author{
Other Ways of being/loving: Rosario Castellanos
}

\author{
Alejandra Moreno Álvarez \\ morenoalejandra@uniovi.es \\ Universidad de Oviedo - España
}

Recibido: 03-03-2017

Aceptado: 26-05-2017

\section{Resumen}

La escritora mejicana Rosario Castellanos (1925-1974) ansiaba otro modo de ser mujer y libre en la sociedad en la que le tocó vivir, convirtiéndose este deseo en el leitmotiv de su obra. En cuanto al amor, se dice que Castellanos estaba convencida de que no podría vivir sin que su marido la amara tanto como ella a él, tal y como ella misma parece indicar en Cartas a Ricardo (1994). La autora concluye uno de sus poemas más conocidos, "Meditación en el umbral", con versos que incitan a la búsqueda de otros modos de ser, siendo mi propósito el de redireccionar ese registro a otros modos de amar. Para ello recurriré a la teoría postestructural de Luce Irigaray, quien hace que nos cuestionemos, al igual que hiciera Castellanos, nuestra identidad, pero que, a diferencia de la escritora mejicana, huye de buscar una respuesta definitoria $y$, en lo referente al amor, profundiza en la búsqueda de una cultura que modifique la condición de las relaciones amorosas. $\mathrm{Y}$ es que otros modos de ser y de amar son posibles.

Palabras clave: Amor, Castellanos, Irigaray.

\begin{abstract}
Mexican writer Rosario Castellanos knew that other ways of being a woman and a free subject were possible, and it was this very desire that became the leitmotiv of her work. Regarding love, it has been said that Castellanos was convinced that it was impossible for her to live without the love of her husband, as she seems to underline in Cartas a Ricardo (1994). She concludes one of her wellknown poems, "Meditación en el umbral", with lines that encourage us to claim new ways of being. It is my purpose to redirect this aim towards new ways of loving within a romantic relationship. To do so I will use Luce Irigaray's poststructuralist theoretical framework on love. This critic makes us question, as Castellanos did, our identity, but differs from the Mexican writer in trying to find an answer and, regarding love, deeply encourages us to deconstruct a culture which should modify romantic relationship stereotypes, since other ways of being and loving are possible.
\end{abstract}

Key words: Love, Castellanos, Irigaray. 


\section{Introducción}

Rosario Castellanos Figueroa (1925-1974), escritora y diplomática, es considerada una de las voces mejicanas más importantes del siglo XX. Tras la muerte de su hermano, huérfana a los veinte años y con medios económicos limitados, halló en la literatura el medio para expresar su pérdida, y consecuente soledad, convirtiéndose en una de las primeras mujeres escritoras de renombre de Chiapas. Será en los años cincuenta cuando emigre a Ciudad de Méjico, graduándose en Filosofía por la Universidad Nacional Autónoma de Méjico.

También estudió Estética en la Universidad de Madrid y pronto pasó a ocupar el puesto de profesora de la Facultad de Filosofía y Letras de la Universidad Autónoma Nacional de Méjico, así como de la Universidad de Wisconsin-Madison, la Universidad Estatal de Colorado y la Universidad de Indiana. Parte de su obra se centra en la defensa de los derechos de las mujeres, de ahí que sea recordada como uno de los símbolos del feminismo latinoamericano. Castellanos murió a los cuarenta y nueve años, en Tel Aviv, donde ejercía como cónsul de Méjico en Israel, víctima de un accidente doméstico, aunque también se especula que pudo haberse suicidado. En el presente artículo, y haciendo uso del leitmotiv por el que Castellanos es conocida,

"Debe haber otro modo que no se llame Safo

ni Mesalina ni María Egipciaca

ni Magdalena, ni Clemencia Isaura.

Otro modo de ser humano y libre.

Otro modo de ser" (Castellanos, 1992: n.p.).

analizaré la construcción del amor y cómo la literatura ofrece nuevos espacios donde otras formas de ser y amar son posibles. Para tal propósito haré uso del estudio de varias de las cartas dirigidas a su marido, Ricardo Guerra, con quien se casó en 1958 para separarse trece años más tarde, y del marco teórico postestructural irigariano.

Dejando a un lado la extensísima obra de Castellanos, que va desde la política, como se recoge en el poemario Lívida Luz (1960), al papel de las mujeres en los espacios públicos, como en el cuento "Lección de cocina" en Álbum de Familia (1971), los escritos feministas, tal y como desarrolla en su obra póstuma de teatro El eterno femenino (1975), las mujeres indígenas "La novela mexicana contemporánea y su valor testimonial" (1960), etc., me centraré en el Bildungsroman en tanto al amor en Castellanos. La autora hace uso de la literatura para dar voz a las mujeres, objetos de conveniencia dominadas por un discurso simbólico y donde el matrimonio, en particular, era, para Castellanos, una forma de suprimir la identidad de las mujeres al no dotarlas de independencia. 


\section{Cartas a Ricardo}

Castellanos escribe setenta y siete cartas dirigidas al que fuera su marido, Ricardo Guerra, entre julio de 1950 y diciembre de 1967, que fueron publicadas veinte años después del fallecimiento de la escritora, en 1994. Una de ellas dice: "[m] e siento mujer y soy feliz de serlo, de estar marcada por ti para siempre; y no me arrepiento y no me avergüienzo y no niego ante nadie, ni ante mi misma, que soy tuya. Te amo Ricardo, te amo mucho, todo lo que soy ahora capaz de amar" (Argentina, octubre de 1950, en Castellanos, 1994: n.p.).

El tono irónico que caracteriza a la escritora, queda eclipsado en muchas de sus cartas por el sufrimiento de un amor no correspondido. Guerra y Castellanos se conocen en la Facultad de Filosofía y Letras de la UNAM, a finales de 1949, y desde la primera carta, el 28 de julio de 1950, Castellanos expresa su amor a Guerra en términos de entrega absoluta.

Tal es el amor de Castellanos por Guerra que llega a decirle "[q]uiero ser para usted, como lo conocí, lo mejor que yo pueda, lo que más se aproxime a lo que usted quiera" (Argentina, octubre de 1950 en Castellanos, 1994: n.p.). De las cartas se deduce que Guerra no correspondía a Castellanos con el mismo amor que Castellanos le profesaba, hecho por el que la autora se culpabilizaba. No obstante, siete años antes de morir, se separa y recupera su yo propio y, con este, el yo poético con tintes autobiográficos y un trasfondo marcadamente político que impregnan su obra. El poeta mejicano Jaime Sabines le dedicó el poema "Recado a Rosario Castellanos" (en Poemas sueltos (1951-1961)), al enterarse de su muerte:

\footnotetext{
"Sólo una tonta podía dedicar su vida a

la soledad y

al amor.

Sólo una tonta podía morirse al tocar

una lámpara,

si lámpara encendida,

desperdiciada lámpara de día eras tú.

Retonta por desvalida, por inerme,

por estar ofreciendo tu canasta de

frutas a los árboles,

tu agua al manantial,

tu calor al desierto,

tus alas a los pájaros,

retonta, rechayito, remadre de tu

hijo y de ti misma.

Huérfana y sola como en las novelas,

presumiendo de tigre, ratoncito,

no dejándote ver por tu sonrisa,
} 
poniéndote corazas transparentes,

colchas de terciopelo y de palabras

sobre tu desnudez estremecida" (Sabines, 2013: n.p.).

Lo que nos llama la atención es cómo la autora de "Meditación en el umbral", que instaba a la apropiación de "otro modo de ser humano y libre, otro modo de ser" (Castellanos, 1992) sea la misma persona a quien Sabines llama "retonta por desvalida" (2013). Bien es sabido que la autora repudiaba "la hipócrita complicidad de hombres y mujeres que se arrellanan en un estatus del que ambos obtienen ventajas" (González Méndez, 2015), los primeros, por mantener su estatus de género dominante; las segundas por no renunciar a ser "las esclavas veneradas"-madre, hija, esposa y amante-(Ibídem). Por ello resulta desconcertante el amor, a veces irracional, que Castellanos manifiesta a Guerra en sus cartas. Misivas que, al mismo tiempo, convierten al público lector en flâneurs, dado que en ellas Castellanos narra cada ciudad que visita, sus lecturas, las películas que visionaba, la gente que conocía, así como sus miedos, deseos y sueños y, sobre todo, las mujeres que las habitaban.

Luisa Posada Kubissa nos recuerda que "bien es sabido que la diferencia entre los sexos es puramente construida y no se deriva de nada, así como de una dualidad natural" (2006: 182). La diferencia construida revalida pues lo-otro, es decir, la alteridad entendida como lo no-idéntico (Deleuze, 1968; Irigaray, 1974). Hemos de analizar, por tanto, lo que no es reductible al discurso logocéntrico y hacer una lectura a contrapelo de lo que siempre ha estado excéntrico al logos, como puede ser el amor; un amor que aquí entendemos como deseo y sentimiento, alejándonos por tanto del amor construido impuesto.

Anna Jónasdóttir en El poder del amor ¿le importa el sexo a la democracia? (1993) diserta sobre cómo las mujeres carecen de autoridad para determinar las condiciones del amor en la sociedad y cómo deben ser sus productos, mientras que el hombre viene a este encuentro no en gran medida para amar, sino para dejarse querer y permitir que a través del amor de ella se quiera a sí mismo (1993: 315). La Real Academia Española ofrece varias definiciones para el concepto de amor que contribuyen a entender el amor como un sentimiento entre dos sujetos donde uno es el activo y otro el pasivo, siendo las mujeres la otredad. Así, dice del amor:

"[...] sentimiento intenso del ser humano que, partiendo de su propia insuficiencia, necesita y busca el encuentro y unión con otro ser; sentimiento hacia otra persona que naturalmente nos atrae y que, procurando reciprocidad en el deseo de unión, nos completa, alegra y da energía para convivir, comunicarnos y crear; sentimiento de afecto, inclinación y entrega a alguien o algo" (RAE: n.p.).

Según dichas acepciones, el sujeto que ama, y que en el caso que nos atañe es Rosario Castellano, busca en el otro, Ricardo Guerra, encuentro, unión, convivencia, entrega, etc. La autora María Luisa Femenías subraya que hay que prestar atención al deseo femenino, jouissance, 
y liberarlo del significante fálico que está implícito en las definiciones señaladas; lo que supone una reinvención de la subjetividad (2000: 172).

Castellanos pensaba, en un principio, que no podría vivir sin el amor de Guerra y el sufrimiento es patente en las misivas que le envía. Las cartas se convierten así en un instrumento que utiliza la autora para "verse, penetrarse, paso necesario en el proceso de auto-configuración de un sujeto" (Pleitez Vela, 2006: 1). Los años de la escritura epistolar se suceden en dos etapas: 1950-1951 y 1966-1967, y dos viajes: Madrid y Wisconsin. En una Castellanos tiene veinticinco y veintiséis años y en la otra cuarenta y uno y cuarenta y dos años.

Partimos de una mujer "obsesionada por amar y ser amada" (Pleitez Vela, 2006: 3) y como ella misma dice: "hambrienta de ternura" (1994), mientras que, en la segunda etapa, se observa a una mujer engañada, traicionada y desesperada por la situación de su matrimonio: "Mi vida, te quiero mucho. No he querido a nadie más que a ti. Me siento muy culpable y muy estúpida por haber echado a perder una relación que pudo haber sido, si no feliz, por lo menos no tan desdichada porque yo siempre, quería otra cosa, comerte, devorarte, no sé qué" (20 de noviembre de 1967, Cuernavaca, en Castellanos, 1994: n.p.). La mujer que escribe desde Wisconsin es mucho más madura, con un matrimonio a sus espaldas marcado por la infidelidad, celos, aborto, intentos de suicidio e internamientos en unidades psiquiátricas. Ricardo Guerra describe así esta etapa:

"[...] en las cartas se ven unas historias sumamente interesantes, sobre todo por la manera como las describe, además de los problemas que tiene con el niño. Cuando Rosario regresa, ya hemos deslindado mucho los problemas que plantea un matrimonio entre gente que tiene cada quien su obra, su vida, y esas cosas; porque no era el caso de un marido que se dedicara a atenderla, o que ella se dedicara a atender a un marido, sino que era algo recíproco, es decir, con formas de actuar y pensar diferentes" (Guerra, 2014: n.p.).

Luce Irigaray, en Ser Dos (1998), donde aborda las relaciones intersubjetivas, afirma, al igual que hiciera Jónasdottir (1993), que existe un camino para que nuevas conductas, cuerpos y lenguajes puedan marcar de una manera no alienada lo femenino y lo masculino. Retomando el pensamiento crítico de autores como Sartre, Merleau-Ponty o Lévinas, entre otros, insta a "amar al otro como un todo, amarlo en su vida sin darle su propia vida. Respetarlo como una fuente surgida de su alteridad" (Irigaray, 1998: 21). Irigaray huye de un pensamiento binario, tratando así de entender el amor como sentimiento y no como herramienta del discurso dominante que convierte a las mujeres en objetos pasivos. Castellanos parte en una primera fase de un sentimiento de culpa que convierte a Guerra "en el espejo ante el cual ella se desnuda y se atreve a mirar su subjetividad contradictoria" (Pleitez Vela, 2006: 8):

"Usted sabe que tuve un hermano y que se murió y que mis padres, aunque nunca me lo dijeron directa y explícitamente, de muchas maneras me dieron a entender que era una injusticia que el varón de la 
casa hubiera muerto y que en cambio yo continuara viva y coleando. Siempre me sentí un poco culpable de existir; durante todos estos años hubiera querido pedir perdón a todos por estar viviendo y me sentía yo culpable en cierto modo de que las cosas hubieran sucedido de ese modo y no del otro que ellos deseaban. Además, constantemente me echaban en cara que si yo no hubiera vivido ellos hubieran podido tranquilamente suicidarse pero que yo los ataba a una vida que no deseaban y que soportaban sólo por su sentido del deber. [...] Allí tiene usted la raíz de todo; una raíz amarga y difícilmente extirpable" (Castellanos, 1994: 36-37).

Las cartas muestran heridas abiertas y cómo Guerra se convierte en el espejo donde ella puede reconocerlas, para de esta manera tratarlas y cicatrizarlas. Por tanto, una de las definiciones que ofrece la RAE del amor, "sentimiento intenso del ser humano que, partiendo de su propia insuficiencia, necesita y busca el encuentro y unión con otro ser" (RAE) correspondería con el sentimiento que en esta primera fase epistolar experimenta la autora.

Así, Castellanos se dio cuenta, tal y como refleja en una segunda etapa epistolar, de que

"[c]onsumir no da una existencia propia; la diferencia, por el contrario, puede garantizarla: soy si tú eres, ser contigo me permite devenir. El dos, este dos, es el de-más que necesito para ser. Encerrarme en una consumación, una posesión, una producción no me hace una. Pero que tú seas y que yo no sea tú, eso me constituye como una, y tal vez incluso como única" (Irigaray, 1998: 25).

Castellanos es consciente de haber interiorizado el amor como "sentimiento hacia otra persona que [...] procurando reciprocidad en el deseo de unión, nos completa, alegra y da energía para convivir, comunicarnos y crear" (RAE) así como "sentimiento de [...] entrega a alguien" (RAE), para llegar a la conclusión de que la consumación o posesión no le hace una y sí un amor que no ansíe el que ella sea Guerra y Guerra sea Castellanos. Es decir, la autora, si bien parte de entender el amor como sujeto que ama y se convierte a la par en objeto pasivo, llega a transgredir la definición del amor desde un punto de vista dicotómico para entenderlo como un sentimiento sin acepciones impuestas.

\section{3. "Lamentación de Dido"}

Motivada por el desamor y el abandono de Ricardo Guerra, Castellanos escribe en 1955, tras la primera etapa epistolar, el poema en prosa: "Lamentación de Dido" (Castellanos, 1957). En este poema épico la autora da voz a Dido, fundadora y primera reina de Cartago. Su fama se debe principalmente al relato incluido en la Eneida de Virgilio que relata cómo Eneas, el líder de Troya, 
llega a Cartago con sus hombres a buscar refugio y Dido, ya viuda, dado que su esposo, Siqueo, había sido asesinado por el hermano de Dido, los acoge.

Dido termina enamorándose de Eneas por voluntad de los dioses, los cuales le hacen pensar que está casada con él. Dido se ve traicionada cuando Eneas la abandona para ir a fundar la ciudad de Roma en las costas italianas. Eneas deja a Dido sumida en un vacío que le lleva a suicidarse sobre una pira, encima de las ropas y otras pertenencias de Eneas, como su espada. En "Lamentación de Dido" Castellanos, rehace diversos mitos acerca de la mujer ya que, a través de este personaje, representa el dilema de mujeres pasadas, presentes y futuras. No en vano aúna a la mujer del mundo clásico con el moderno, visibilizando la situación universal de las mujeres. Este poema, que Julian Palley define como el primer monólogo dramático de Castellanos (1988: 36) plasma "la encrucijada en la que se encuentra la mujer al verse confrontada con normas sociales que no son compatibles con su realidad biológica y espiritual" (Sesana).

Al mostrar el dilema de toda mujer en la sociedad que le ha tocado vivir, ya que Dido desea a Eneas pero la sociedad le impone fidelidad al marido difunto, Castellanos muestra su propia disyuntiva, aunque no sólo se circunscribe a la experiencia personal. Gabriela de Beer sugiere que Dido es una máscara tras la cual Castellanos quiso reflejar un momento particular de su vida (1981) y Perla Schwartz (1984: 64) llega incluso a describir a Dido como el alter ego de Castellanos, una "Dido- Rosario", que se revela contra el discurso dominante creado donde las mujeres son convertidas en otredad. Así, según Frank Dauster (1987), Castellanos alcanza a controlar los sentimientos y emociones del hablante, Dido, dado el paralelismo de estos para con los suyos propios.

La profundidad del sentimiento que parece expresar Dido contrasta con el lenguaje coloquial que Castellanos utiliza en "Lamentación de Dido" acentuando así la diferencia entre la mujer del mundo clásico con la de la mujer moderna. Castellanos da voz a un personaje víctima de una sociedad patriarcal que impone a la viuda un comportamiento acorde a su estatus, y que no es otro que el de la fidelidad, pero Dido, aún una mujer joven, tiene necesidades tanto de compañerismo como de sexualidad (Sesana, 2016). Es interesante ver cómo este poema, escrito entre 1951 y 1953 , periodo que constituye el intermedio entre las dos etapas epistolares, bebe de la primera y también proyecta lo que será una segunda etapa. Así se ve esa evolución propia del Bildungsroman donde Castellanos da voz a Dido, que dice:

\footnotetext{
"Y yo amé a aquel Eneas, a aquel hombre de promesa

jurada ante otros dioses.

Lo amé con mi ceguera de raíz, con mi soterramiento

de raíz, con mi lenta fidelidad de raíz.

No, no era la juventud. Era su mirada lo que así me

cubría de florecimientos repentinos [...]" (“Lamentación de Dido", 1957: n.p.)
} 
Castellanos muestra a un personaje desolado ante la pérdida de su amado, Eneas, pero, al mismo tiempo, presenta a un sujeto consciente de su "ceguera" motivada por el discurso dominante. En palabras de Irigaray, "[t]odavía nos falta esa cultura intersubjetiva, y caemos sin cesar en la dicotomía sujeto/objeto y, más generalmente, en la lógica de la oposición binaria [...] donde la sensibilidad ya no es un sentir entre sujetos presentes, sino un experimentar en el cual el sujeto se reduce a un "objeto" que provoca o experimenta la sensación" (1998: 66). Castellanos está atenta a las tres dimensiones que propone Irigaray cuando percibimos "al (a la) otro(a)" (1998: 66): "las cualidades del sujeto que percibe, el otro presente a mí como objeto de percepción, el otro en tanto es y debe seguir siendo sujeto" (1998: 66). Según Castellanos, la primera dimensión está representada por Dido, sujeto creado por la tradición mitológica y literaria, donde, en la Eneida de Virgilio, carece de voz propia, voz que le proporcionará Castellanos en "Lamentación de Dido"; el otro presente a mí como objeto de percepción son para Castellanos, una vez transcurrida la "ceguera", Dido y Eneas, respectivamente; el otro en tanto es y debe seguir siendo sujeto son también Dido y Eneas. Dido reconoce que:

“Ah, sería preferible morir. Pero yo sé que para mí no hay muerte. Porque el dolor- —y qué otra cosa soy más que dolor?

—me ha hecho eterna.” (“Lamentación de Dido”, 1957: n.p.)

Castellanos hace a Dido eterna y, dado que "debe haber otro modo que no se llame Safo ni Mesalina ni María Egipciaca ni Magdalena ni Clemencia Isaura”, permite que Dido sufra pero que no se suicide, como así ocurre en la Eneida. Castellanos crea un espacio posible para el imaginario femenino en el cual puede la mujer ser sujeto de su propio deseo ya que, otras formas de ser y de amar son posibles. Tanto Dido como Rosario Castellanos reinventan el amor, llegando a la conclusión, en palabras de Irigaray de que "[e]s necesario amar lo suficiente para engendrar y no herir - amar al otro como un todo, amarlo en su vida sin darle su propia vida- Respetarlo como una fuente surgida de su alteridad" (Irigaray, 1998: 21). 


\section{BIBLIOGRAFÍA}

- Castellanos, Rosario (1957): Poemas (1953-1955). Méjico: Colección Metáfora. . (1992): Meditación en el umbral: antología poética. Madrid: S.L. Fondo de Cultura Económica de España. (1994): Cartas a Ricardo. Méjico: Conaculta

- Dauster, Frank (1987): The Double Standard: Five Contemporary Mexican Poets. Kentucky: University Press of Kentucky.

- De Beer, Gabriella (1981): "Feminismos en la obra poética de Rosario Castellanos". En Revista Crítica Literaria Latinoamericana, $\mathrm{n}^{\circ}$. 13, pp. 105-112.

- Deleuze, Gilles (1988) [1968]: Diferencia y repetición. Madrid: Júcar.

- Femenías, María Luisa (2000): Sobre sujeto y género. Lecturas feministas desde Beauvoir a Butler. Buenos Aires: Catálogos.

- Irigaray, Luce (1994) [1974]: Speculum. Espéculo de la otra mujer. Madrid: Saltés. . (1998) [1997]: Ser dos. Buenos Aires: Paidós. (2002): The Way we Love. London: Continuum.

- Jónasdotti, Anna G. (1993): El poder del amor ¿le importa el sexo a la democracia? Madrid: Ediciones Cátedra.

- Guerra, Ricardo (2014): "Epistolario de Rosario Castellanos a Ricardo Guerra". Entrevista a Ricardo Guerra. En: La Unión de Morelos, 22 de septiembre de 2014. Disponible en: https://www.launion.com.mx/expos/noticias/60666-epistolario-de-rosario-castellanos-a-ricardoguerra.html [12/12/2016].

- González Méndez, José (2015): "Rosario Castellanos ante el espejo". En: Milenio, 25 de mayo de 2015. Disponible en: http://www.milenio.com/cultura/Rosario-Castellanosespejo_0_524347570.html [06/01/2017].

- Palley, Julian (1988): Meditation on the Threshhold. USA: BilingualPress.

- Pleitez Vela, Tania (2006): “'Diario de España' en las cartas de Rosario Castellanos”. Conferencia de Tania Vela Pleitez en el Congreso Internacional: Las palabras y los días. Un enfoque comparatista del diario. Universidad de Córdoba, febrero de 2006. Disponible en: http://www.academia.edu/1673257/_Diario_de_Espa\%C3\%B1a_en_las_cartas_de_Rosario_Ca stellanos [12/12/2016].

- Posada Kubissa, Luisa (2006): "Diferencia, identidad y feminismo: una aproximación al pensamiento de Luce Irigaray”. En: Logos. Anales del Seminario de Metafísica. vol. 39 pp. 181201.

- Sabines, Jaime (2013): Poemas Sueltos (1951-1961). Méjico: Grupo Planeta.

- Sesana, Laura (2016): "La poesía de Rosario Castellanos: la sexualidad vs. la sociedad". En: Lasesana. Disponible en: https://lasesana.com/other/spanish-articles-papers-and-booksummaries/la-poesia-de-rosario-castellanos-la-sexualidad-vs-la-sociedad/ [13.01.2017]

- Schwartz, Perla (1984): Rosario Castellanos, mujer que supo latín. Méjico: Katún. 